\title{
Paired Trial of Cyclophosphamide and Prednisone in Children with Nephrosis
}

\author{
Y. C. TSAO and C. H. YEUNG \\ From the Department of Paediatrics, University of Hong Kong
}

\begin{abstract}
Tsao, Y. C., and Yeung, C. H. (1971). Archives of Disease in Childhood, 46, 327. Paired trial of cyclophosphamide and prednisone in children with nephrosis. Cyclophosphamide and prednisone were compared as the primary treatment for the nephrotic syndrome in 27 boys and 4 girls. The patients, aged between $2 \frac{1}{2}$ and 11, were paired according to their renal histology; 19 belonged to the minimal change type, 8 to the mild proliferative type, and 4 had diffuse membranous glomerulonephritis but with selective type of proteinuria. The two groups of patients were comparable as regards period of observation before treatment, and duration of follow-up. About half the patients of each group went into spontaneous diuresis, or had no fluid retention, before treatment was started.

Cyclophosphamide induced a remission more slowly than prednisone, but remission was less likely to be followed by relapse. Two patients treated with prednisone and one treated with cyclophosphamide still had persistent proteinuria at the time of review.

The incidence of cyclophosphamide resistance in nephrosis remains unknown, but is probably not high. Among patients who responded to treatment, duration of persisting proteinuria varied widely, and therefore slow response must be distinguished from true resistance to treatment.

Cyclophosphamide should be useful in all patients who relapse after a steroidinduced remission, but its use must be balanced against potential long-term hazards.
\end{abstract}

Though the outlook for children with nephrosis has improved considerably since the advent of steroid therapy, there remains a small but significant number of patients who are either unresponsive to steroid therapy or have frequent relapses. Two recent long-term follow-up studies of children treated with steroids have shown that $9 \%$ and $25 \%$ died within 5 years (Cornfeld and Schwartz, 1966; Arneil and Lam, 1966). On the premise that immune mechanisms may be involved in the genesis of the nephrotic syndrome, cytotoxic agents have been used to treat such patients since 1949 (Chasis, Goldring, and Baldwin). Initially, only short courses were employed (Kelley and Panos, 1952; Baldwin et al., 1953), and though immediate results were encouraging, attempts to induce long remissions were less successful. In the past decade there has been a new upsurge of interest in the use of such 'immunosuppressive agents' in the nephrotic syndrome (Coldbeck, 1963;

Received 31 December 1970.
Grupe and Heymann, 1966; West, Hong, and Holland, 1966; Etteldorf et al., 1967; and Moncrieff et al., 1969) and better results have been achieved. However, most of the trials have been carried out in patients who have had steroid therapy, and no attempt has been made to assess the efficacy of this form of therapy when given from the start.

While recognizing the potential hazards of cytotoxic agents, it must be remembered that drug therapy of nephrosis in children is still entirely empirical, since the action of steroid and cytotoxic agents in this condition is unknown. Of the varieties of nephrosis where there is some evidence of an underlying immunological mechanism, such as nephrotic syndrome associated with quartan malaria (Soothill and Hendrickse, 1967; and Ward and Kibukamusoke, 1969), infected ventriculoatrial shunts (Black, Challacombe, and Ockenden, 1965; Stickler et al., 1968), and post-streptococcal glomerulonephritis (Michael et al., 1966), response to steroid therapy has generally been poor. On the other hand, in idiopathic nephrotic syndrome 
with minimal histological changes under light microscopy, evidence for an underlying immunological mechanism is usually lacking, viz. the serum $\beta_{1 \mathrm{c}}$ globulin level is normal and immunofluorescent staining for deposition of $\beta_{1 \mathrm{c}}$ and the immunoglobulins on the glomerular basement membrane are negative. These facts provide stimuli to find better methods of treating nephrosis than administering steroids.

Before rationally empirical use can be made of cytotoxic agents, their effects on uncomplicated cases must be known. The present study is designed to compare the efficacy of this form of treatment with that of prednisone. Circumstances have made it impossible both ethically and from the practical standpoint to include a control untreated group. No attempt is made to compare the various cytotoxic agents, cyclophosphamide being used throughout this study because our previous experience has shown it to be the most suitable for prolonged maintenance.

\section{Material and Methods}

Thirty-one patients, 26 boys and 5 girls, admitted over a 22-month period (from January 1968 to November 1969) were included in this study. Their ages ranged from $2 \frac{1}{2}$ to 11 years. The minimum observation period was 7 months. Patients with nephrotic syndrome secondary to Schönlein-Henoch syndrome, acute glomerulonephritis, and systemic lupus erythematosus were excluded. All the patients had a renal biopsy before starting treatment. The technique and histological classification were as reported previously (Tsao, Chan, and Gibson, 1969). Patients with severe proliferative changes in their renal biopsy were excluded because they are known to respond poorly to steroids (White, Cameron, and Trounce, 1966; and Tsao et al., 1969). Patients with diffuse membranous glomerulonephritis were included if they also showed a selective type of proteinuria (Chan and Tsao, 1966). An initial observation period was instituted to exclude those about to undergo spontaneous remission, and to exclude tuberculosis and other forms of infection. Treatment was postponed whenever there was a febrile illness.

Nineteen patients were classified as 'minimal change', 8 as 'mild proliferative', and 4 as 'diffuse membranous glomerulonephritis'. They were assigned alternately to the two treatment groups according to their renal histology.

Cyclophosphamide was used at the dose of $3-5 \mathrm{mg} / \mathrm{kg}$ per day. The dose was adjusted so as to keep the white blood cell count just above $4,000 / \mathrm{mm}^{3}$. The course varied in individual patients from 6 months to 19 months. Prednisone was used at an initial dose of $2 \mathrm{mg} / \mathrm{kg}$ per day. This was maintained until the patient showed a significant reduction in proteinuria. The dose was then gradually reduced to half and maintained at this level until the blood chemistry had returned to normal or reached a steady state. It was then further reduced to 10 to $20 \mathrm{mg}$ daily and maintained for 6 to 12 months at this level.

Results
As seen in the Table, the two groups of patients

TABLE

Comparison of Patients Treated with Cyclophosphamide or Prednisone

\begin{tabular}{|c|c|c|}
\hline & Cyclophosphamide & Prednisone \\
\hline $\begin{array}{c}\text { Total number of } \\
\text { patients } \\
\text { With initial } \\
\text { remission } \\
\text { Relapsed } \\
\text { With persistent } \\
\text { proteinuria }\end{array}$ & $\begin{array}{r}15 \\
14 \\
0 \\
1\end{array}$ & $\begin{array}{r}16 \\
14 \\
6 \\
2\end{array}$ \\
\hline $\begin{array}{l}\text { Renal histology: } \\
\text { Minimal change } \\
\text { Mild proliferative } \\
\text { Diffuse } \\
\text { membranous }\end{array}$ & $\begin{array}{l}9 \\
4 \\
2\end{array}$ & $\begin{array}{r}10 \\
4 \\
2\end{array}$ \\
\hline $\begin{array}{l}\text { Observation period } \\
\text { before treatment } \\
\text { (wk) } \\
\text { (a) patients with no } \\
\text { post treatment } \\
\text { weight loss } \\
\text { (b) patients with } \\
\text { diuresis }\end{array}$ & $\begin{array}{l}(\mathrm{m}=3 \cdot 2, \mathrm{n}=15) \\
(\mathrm{m}=3 \cdot 2, \mathrm{n}=6) \\
(\mathrm{m}=3 \cdot 2, \mathrm{n}=9)\end{array}$ & $\begin{array}{l}(m=2 \cdot 0, n=16) \\
(m=1 \cdot 9, n=8) \\
(m=2 \cdot 1, n=8)\end{array}$ \\
\hline $\begin{array}{l}\text { Time taken to reach } \\
\text { 'dry weight' (dy) } \\
\text { Fluid retention (as } \\
\% \text { 'dry weight) }\end{array}$ & $\begin{array}{c}11-33 \\
(\mathrm{~m}=20, \mathrm{n}=9) \\
6 \cdot 0-40 \cdot 0 \\
(\mathrm{~m}=19 \cdot 5 \%, \mathrm{n}=9)\end{array}$ & $\begin{array}{c}8-29 \\
(m=16, n=8) \\
6 \cdot 8-42 \cdot 0 \\
(m=20 \cdot 4 \%, n=8)\end{array}$ \\
\hline $\begin{array}{l}\text { Duration of initial } \\
\text { proteinuria after } \\
\text { start of treatment } \\
\text { (mth) }\end{array}$ & $(m=3 \cdot 9, n=14)$ & $(m=2 \cdot 4, n=14)$ \\
\hline $\begin{array}{l}\text { Duration of follow- } \\
\text { up after start of } \\
\text { treatment (mth) }\end{array}$ & $\begin{array}{c}9-26 \\
(m=16 \cdot 5, n=15)\end{array}$ & $(m=17 \cdot 9, n=16)$ \\
\hline
\end{tabular}

were comparable as regards histological appearance, initial observation period before treatment, and total duration of follow-up. $40 \%$ of the patients assigned to the cyclophosphamide group and 50\% of the patients assigned to the prednisone group either had a spontaneous diuresis or had negligible fluid retention in the period of observation before treatment was started. Their period of observation before treatment was not, on average, different from that of the remaining patients who had no spontaneous diuresis.

For the patients who had no spontaneous diuresis, the time taken to reach dry weight after . 
the start of treatment was 20 days for cyclophosphamide and 16 days for prednisone (Fig. 1). The

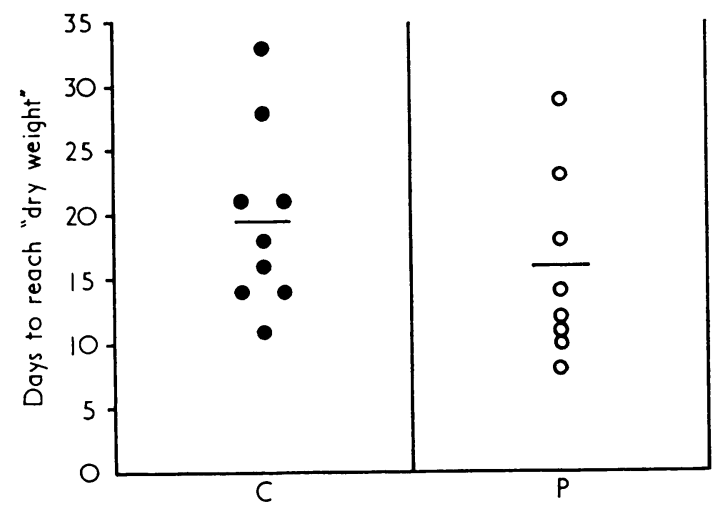

FIG. 1.-Time taken to reach 'dry weight'. The cross bars represent the arithmetic mean for each group. $C=$ cyclophosphamide-treated, $P=$ prednisone-treated.

trend suggests that diuresis may be induced earlier in prednisone-treated patients, but the difference is not significant $(P>0.05$, D.F. 15). The mean fluid retention for the two treatment groups was the same, about $20 \%$ of the dry weight.

Two of the patients on prednisone and one of the patients on cyclophosphamide still had proteinuria at the time of review. These apart, the mean duration of proteinuria was 3.9 months for the cyclophosphamide treated group and $2 \cdot 4$ months for the prednisone treated group. The difference becomes more impressive when their distributions are compared (Fig. 2). Of the patients treated with prednisone, all but 2 lost their proteinuria within 3 months of starting treatment, but the patients treated with cyclophosphamide lost theirs at various times throughout a period of 7 months. The results suggest that prednisone tends to induce a full remission in a shorter time than cyclophosphamide.

Six patients treated with prednisone relapsed after $4,8,11,12,12$, and 14 months in remission. but none of those treated with cyclophosphamide who made a remission had relapsed during the observation period. The mean duration of full remission was 10.9 months for the cyclophos-

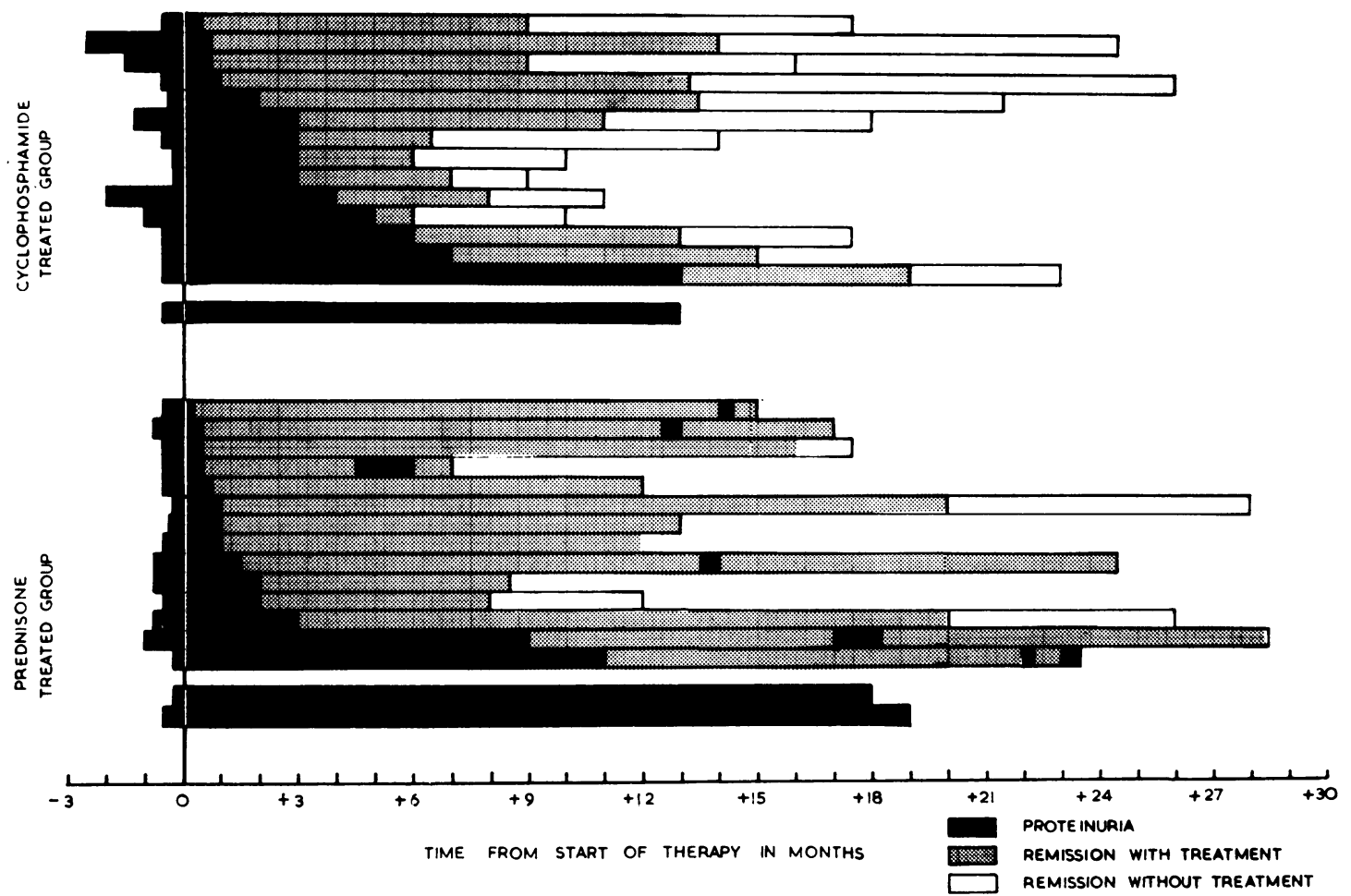

FIG. 2.-Details of follow-up of individual patients, including the duration of proteinuria, length of treatment, and the observation period before and after treatment. 
phamide treated group, and 12.6 months for the prednisone treated group. The slight difference is accounted for by the shorter period of proteinuria in the prednisone group. Otherwise, the two groups are comparable. The large difference in the relapse rate must be attributed to the different effects of the two treatments.

\section{Discussion}

The use of cyclophosphamide as the primary treatment of nephrosis in children enables its effects to be assessed more easily. The present study shows that, contrary to the conclusion of Grupe and Heymann (1966), cyclophosphamide is effective when it is used alone without steroids. The short-term effects of cyclophosphamide and prednisone on children with nephrosis were very similar. The main advantage of cyclophosphamide therapy in the short term was the absence of relapse in the 15 patients so treated. In contrast, 6 of the 14 patients who responded initially to prednisone relapsed. The follow-up period is still not long enough to say whether the absence of relapse in the cyclophosphamide group is due to a longer period of remission, or to a reduction in the total incidence of relapse.

Two patients with minimal change in their renal histology who were steroid treated still have proteinuria 17 and 18 months after the start of treatment. This incidence of steroid resistance corresponds with our previous findings in a larger series (Tsao et al., 1969) and with our long-term follow-up studies. All except one of the patients treated with cyclophosphamide have attained remission. The exception is a patient with minimal change in his renal histology; he started treatment 12 months ago, and the proteinuria has become intermittent in the past 5 months. In the remaining patients the time taken to reach full remission varied from 2 weeks to 13 months. Treatment has been maintained throughout this period. The results emphasize the need to distinguish 'slow responders' from 'non-responders' and also suggest that therapeutic failure as commonly defined is only a relative term. Apart from the drug employed and the dosage and duration of treatment, it also depends on the time limit set for a response to occur. When the slow responders are excluded, the incidence of true resistance to cyclophosphamide is probably not high, but proper assessment can only be made when its use is more widely adopted.

Such definition of drug resistance is also critical in the interpretation of the results of any therapeutic trial. Thus, if 8 weeks is set as the time limit for a response to occur, 5 out of the 16 patients treated with prednisone and 10 out of the $15 \stackrel{\rho}{?}$ patients treated with cyclophosphamide would be labelled as 'non-responders'. At 6 months from $\overrightarrow{\vec{F}}$ the start of treatment, the corresponding figures for the 'non-responders' would be 4 for the prednisonetreated group and 3 for the cyclophosphamidetreated group. The failure of azathioprine to $\vec{\curvearrowright}$ produce any significant advantage over the placebo $\triangle$ in the international study (Abramowicz et al., के 1970) may be attributed partly to this phenomenon. $\vec{\circ}$

Our finding that patients treated primarily with cyclophosphamide relapse less than those treated with prednisone is similar to the results of other workers who used cyclophosphamide on steroidtreated frequent relapsers (West et al., 1966; Grupe and Heymann, 1966; Etteldorf et al., 1967, and Moncrieff et al., 1969). There is, therefore, little advantage in using cyclophosphamide as the primary treatment of childhood nephrosis. However, if proteinuria is accepted as evidence of activity of the disease and if better results are to be obtained, it seems reasonable to suggest using cyclophosphamide in all patients who relapse after a steroid-induced remission. On the other hand, the potential hazards of cyclophosphamide must be recognized, particularly its effect on the immature gonads. Until its long-term risks are known, some may argue that cyclophosphamide should be reserved for patients who show signs of steroid toxicity.

The optimal duration of cyclophosphamide therapy is not established. West et al. (1966) have commented on the failure of earlier trials using cytotoxic agents, especially nitrogen mustard, to attain prolonged remission, and have related it to the inability to maintain therapy for an adequate period of time. Moncrieff et al. (1969) regarded 3 months as the minimum length of treatment for the frequent relapsers. In this study, the treatment has been continued for a minimum of 6 months. The advantage of a longer period of treatment is shown by the total absence of relapse over a comparable duration of follow-up.

Recently, Barratt and Soothill (1970) reported that it was possible to maintain the remission in steroid-sensitive relapsers with a short course of cyclophosphamide. Their patients were all in steroid-induced remission when cyclophosphamide was started. This may prove to be a better way of achieving maximum result with the minimum amount of cyclophosphamide and may prove more acceptable to the critics of cyclophosphamide therapy.

We would like to express our thanks to Professor C. E. Field for her keen interest in this study, to Dr. 
V. Yu for drawing the diagrams, and to Dr. G. H. Choa, the Director of Medical and Health Services, Hong Kong, for permission to publish.

Correspondence to Dr. Y. C. Tsao, Department of Paediatrics, Queen Mary Hospital, Hong Kong.

\section{REFERENCES}

Abramowicz, M., Arneil, G. C., Barnett, H. L., Barron, B. A., Edelmann, C. M., Jr., Gordillo-P., G., Greifer, I., Hallman, N., Kobayashi, O., and Tiddens, H. A. (1970). Controlled trial of azathioprine in children with nephrotic syndrome. Lancet, $1,959$.

Arneil, G. C., and Lam, C. N. (1966). Long-term assessment of steroid therapy in childhood nephrosis. Lancet, $2,819$.

Baldwin, D. S., McLean, P. G., Chasis, H., and Goldring, W. (1953). Effect of nitrogen mustard on clinical course of glomerulonephritis. Archives of Internal Medicine, 92, 162.

Barratt, T. M., and Soothill, J. F. (1970). Controlled trial of cyclophosphamide in steroid-sensitive relapsing nephrotic syndrome of childhood. Lancet, $2,479$.

Black, J. A., Challacombe, D. N., and Ockenden, B. G. (1965). Nephrotic syndrome associated with bacteraemia after shunt operations for hydrocephalus. Lancet, $2,921$.

Chan, W. C., and Tsao, Y. C. (1966). Diffuse membranous glomerulonephritis in children. Fournal of Clinical Pathology, $19,464$.

Chasis, H., Goldring, W., and Baldwin, D. S. (1949). Effects of febrile plasma, typhoid vaccine and nitrogen mustard on renal manifestations of human glomerulonephritis. Proceedings of the Society of Experimental Biology and Medicine, 71, 565.

Coldbeck, J. H. (1963). Experience with alkylating agents in the treatment of children with the nephrotic syndrome. Medical fournal of Australia, 2, 987.

Cornfield, D., and Schwartz, M. W. (1966). Nephrosis: a longterm study of children treated with corticosteroids. Fournal of Pediatrics, 68, 507.
Etteldorf, J. N., Roy, S., III, Summitt, R. L., Sweeney, M. J. Wall, H. P., and Berton, W. M. (1967). Cyclophosphamide in the treatment of idiopathic lipoid nephrosis. Fournal of Pediatrics, 70, 758.

Grupe, W. E., and Heymann, W. (1966). Cytotoxic drugs in steroid-resistant renal disease. American fournal of Diseases of Children, 112, 448.

Kelley, V. C., and Panos, T. C. (1952). The nephrotic syndrome in children. I. Clinical response to nitrogen mustard therapy. fournal of Pediatrics, 41, 505.

Michael, A. F., Jr., Drummond, K. N., Good, R. A., and Vernier, R. L. (1966). Acute poststreptococcal glomerulonephritis: immune deposit disease. Fournal of Clinical Investigation, 45, 237.

Moncrieff, M. W., White, R. H. R., Ogg, C. S., and Cameron, J. S. (1969). Cyclophosphamide therapy in the nephrotic syndrome in childhood. British Medical fournal, 1, 666.

Soothill, J. F., and Hendrickse, R. G. (1967). Some immunological studies of the nephrotic syndrome of Nigerian children. Lancet, 2, 629.

Stickler, G. B., Shin, M. H., Burke, E. C., Holley, K. E., Miller, R. H., and Segar, W. E. (1968). Diffuse glomerulonephritis associated with infected ventriculoatrial shunt. New England fournal of Medicine, 279, 1077.

Tsao, Y. C., Chan, W. C., and Gibson, J. B. (1969). Persistent proteinuria in children. Archives of Disease in Childhood, 44, 443.

Ward, P. A., and Kibukamusoke, J. W. (1969). Evidence for soluble immune complexes in the pathogenesis of the glomerulonephritis of quartan malaria. Lancet, 1, 283.

West, C. D., Hong, R., and Holland, N. H. (1966). Effect of cyclophosphamide on lipoid nephrosis in the human and on aminonucleoside nephrosis in the rat. Fournal of Pediatrics, 68, 516.

White, R. H. R., Cameron, J. S., and Trounce, J. R. (1966). Immunosuppressive therapy in steroid-resistant proliferative glomerulonephritis accompanied by the nephrotic syndrome. British Medical fournal, 2, 853. 